\title{
Five Years Follow-up of a Spontaneous Eruption of an Impacted Mandibular Premolar Associated with a Dentigerous Cyst Treated by Marsupialization
}

\author{
Samia Aboujaoude ${ }^{1}$, Maryse Ziade ${ }^{2}$, Georges Aoun ${ }^{3}$ \\ 1. Pediatric Dentistry and Public Dental Health, Lebanese University, Beirut, LBN 2. Oral Surgery, Lebanese University, \\ Beirut, LBN 3. Oral Medicine and Maxillofacial Radiology, Lebanese University, Beirut, LBN
}

Corresponding author: Georges Aoun,dr.georgesaoun@gmail.com

\begin{abstract}
Dentigerous cysts (DC) are developmental odontogenic cysts associated with impacted or partially erupted teeth; they can occur at any location of the jaw. Being generally asymptomatic, they are fortuitously discovered when radiographs are taken to investigate a tooth eruption failure. In this report, we present a case of a 10-year-old girl presented with the absence of the right second mandibular premolar and retention of the right second primary molar. After clinical and radiological examinations a preliminary diagnosis of the DC was made and confirmed later histopathologically. The lesion was treated by marsupialization to allow eruption of the affected tooth and followed up for five years with no evidence of recurrence.
\end{abstract}

Categories: Dentistry

Keywords: dentigerous cyst, marsupialization, follow-up

\section{Introduction}

A dentigerous cyst (DC) is a developmental odontogenic cyst associated with impacted or partially erupted teeth [1]. It is considered the second most common cyst of the oral cavity after the radicular cyst [2-3].

A DC can occur at any location of the jaw but it is commonly seen in relation to mandibular third molars followed by the maxillary canines and the maxillary third molars [3-6]. Its formation is described as a result of fluid accumulation between the enamel reduced epithelium and the developing tooth crown [7].

Clinically, patients with DC are usually asymptomatic unless the cyst becomes secondarily infected $[2,7]$. Thus, most of the DCs are discovered fortuitously when radiographs are taken to investigate a tooth eruption failure [7].

Received 03/16/2020 Review began 03/18/2020 Review ended 03/20/2020 Published 03/22/2020

\section{Copyright 2020}

Aboujaoude et al. This is an open access article distributed under the terms of the Creative Commons Attribution License CC-BY 4.0., which permits unrestricted use, distribution, and reproduction in any medium, provided the original author and source are credited.
Radiographically, most DCs present as a well-defined unilocular radiolucent lesion arising at the cementoenamel junction and surrounding the crown of an impacted tooth $[2,4,6]$.

Many cysts and tumors with radiological appearances related to an embedded tooth may constitute a differential diagnosis challenge for DC. Dental follicle remains the most prominent condition; it can be ruled out as, contrary to DC's size, it does not exceed 3-4 mm [8]. Odontogenic keratocyst and unicystic ameloblastoma can also be considered; however, a difference exists between these two lesions and DC considering the attachment point to the embedded tooth [9].

Treatment modalities of DC are enucleation and decompression/marsupialization; however, despite the favorable prognosis of DC whatever the surgical technique is, some important factors must be considered for the treatment plan, such as DC size and proximity to anatomic structures, the patient's age, and the possibility of saving the involved tooth [2,6,10-12]. Therefore, marsupialization in pediatric dentistry was preferred based on the higher tooth eruption potential in children with teeth open apices [12-13].

This report describes a case of a DC associated with a second right mandibular premolar of a 10-year-old girl treated by marsupialization and followed up for five years.

\section{Case Presentation}

A 10-year-old girl presented to our specialized dental office, along with her parents, complaining from pain when chewing on the right side. Medical and physical examinations revealed a healthy girl with no extraoral findings. Intra-orally, the right second mandibular premolar was absent, with retention of the right second primary molar. On palpation, moderate pain was felt at the vestibule of the region. The overlying mucosa was normal in color and texture (Figure 1). 


\section{Cureus}

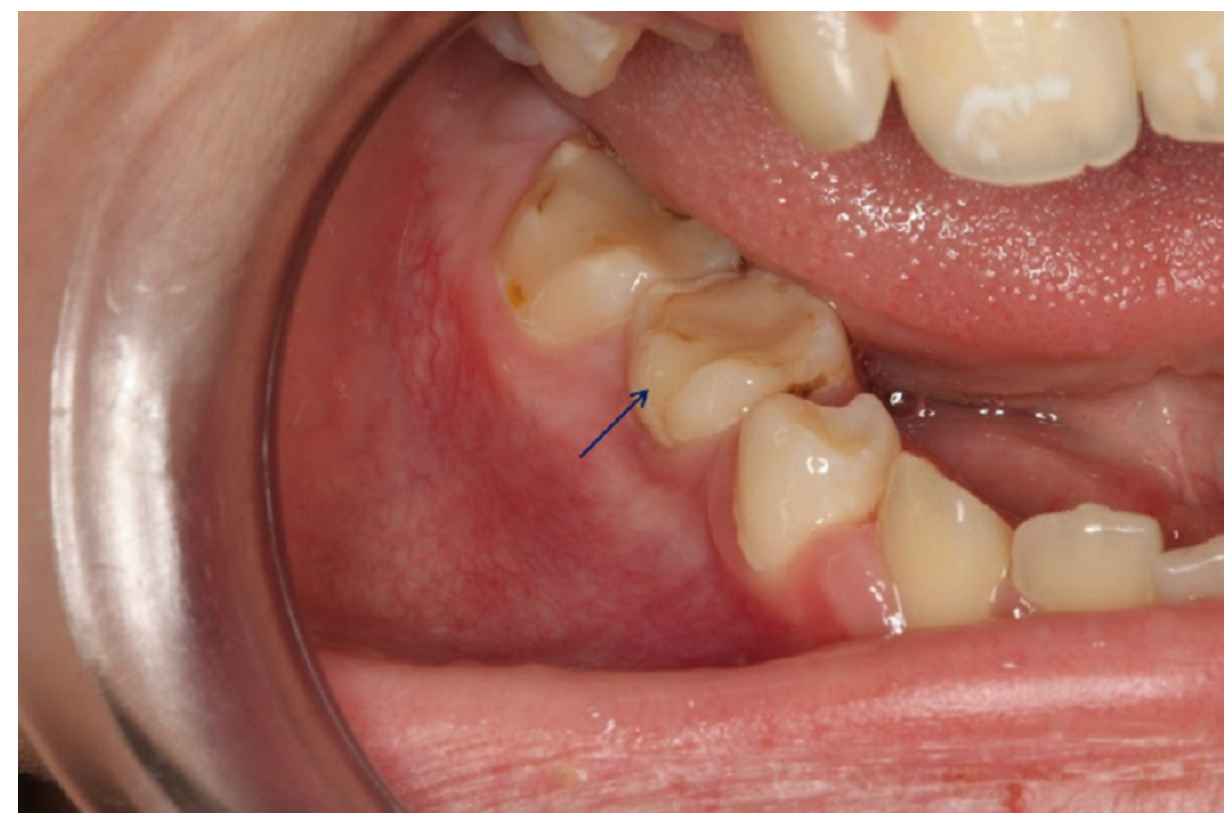

\section{FIGURE 1: Intraoral photograph}

Intraoral photograph showing the retention of the second primary molar (blue arrow) with normal overlying mucosa of the vestibule of the right mandibular region

No regional lymphadenopathy was noticed. The panoramic radiograph showed a well-defined unilocular radiolucent lesion in the right side of the body of the mandible associated with the impacted second premolar (Figure 2).

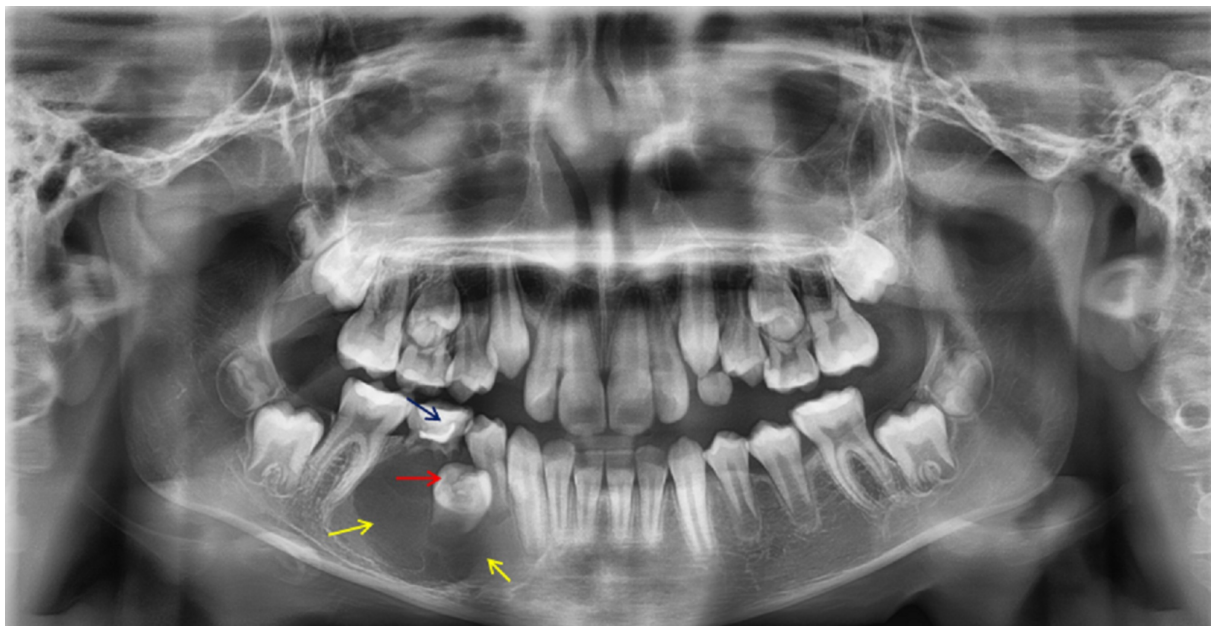

\section{FIGURE 2: Panoramic radiograph}

A panoramic radiograph showing a well-defined unilocular radiolucent lesion (yellow arrows) in the right side of the body of the mandible associated with the impacted second premolar (red arrow) and retention of the second primary molar (blue arrow)

Considering the patient's age, the cyst size and the developmental stage of the involved tooth treatment by marsupialization was effectuated after extraction of the second primary molar.

The process consisted in suturing the edges of the socket induced by the extracted tooth in order to create a communication with the oral cavity allowing a freely continuous draining; sterile gauze was inserted inside the site and replaced weekly (Figure 3). 


\section{Cureus}
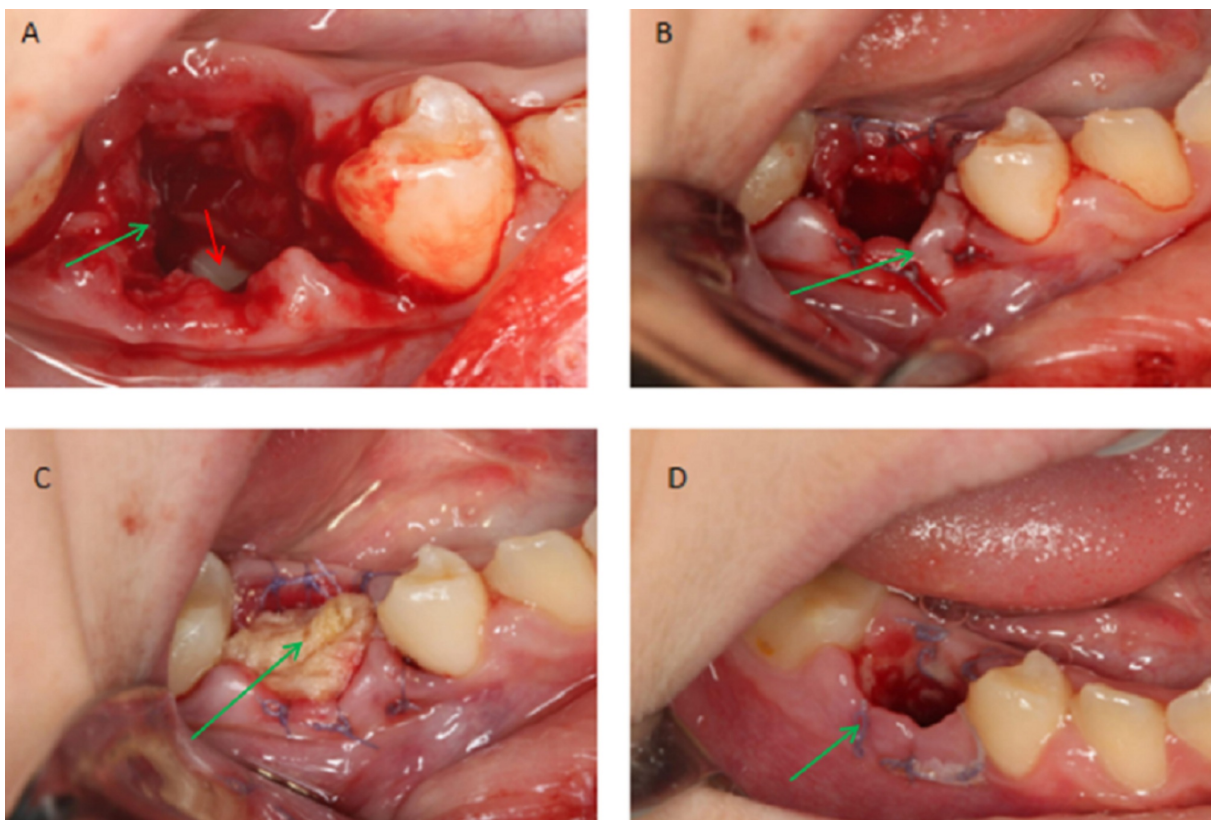

\section{FIGURE 3: Intraoral photographs}

Intraoral photographs showing the different steps of the marsupialization (green arrows) after extraction of the second primary molar; to note the position of the involved tooth 45 deep inside the cavity (red arrow)

Histopathologically, the excisional specimen was compatible with a dentigerous cyst.

The patient showed complete regression of the lesion and eruption of the involved tooth 45 ; she remained recurrence-free clinically and radiologically after a follow up for a period of 5 years (Figures 4-6).

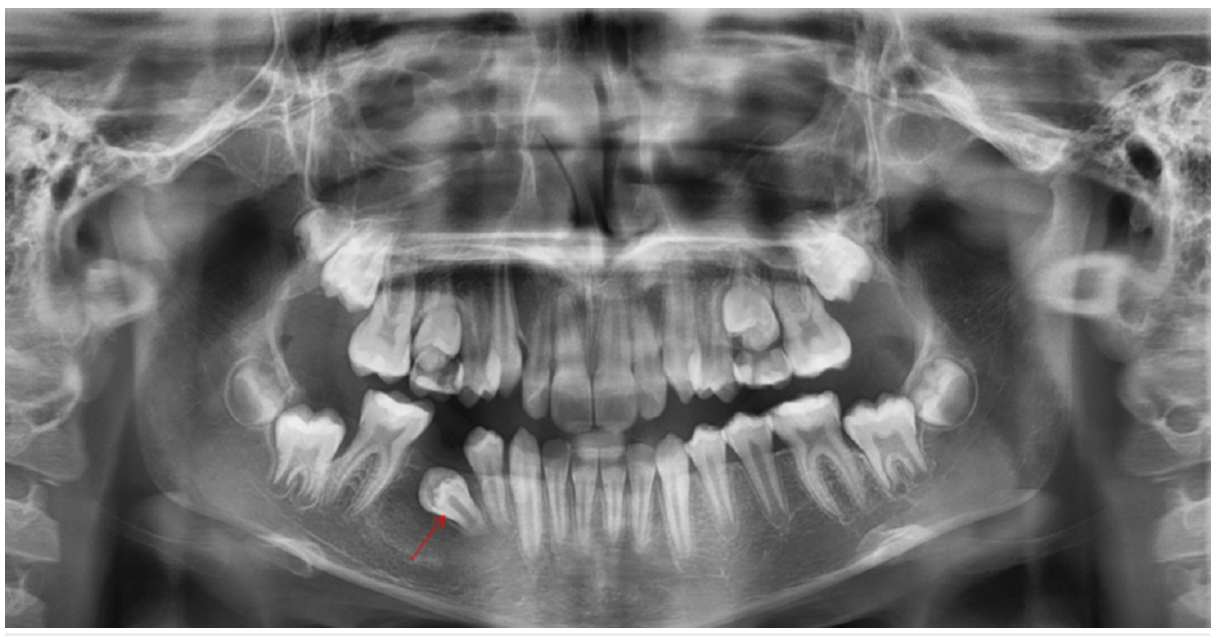

\section{FIGURE 4: Panoramic radiograph}

A panoramic radiograph taken after 9 months from the surgery showing regression of the lesion and the new position of the involved tooth 45 (red arrow) 


\section{Cureus}

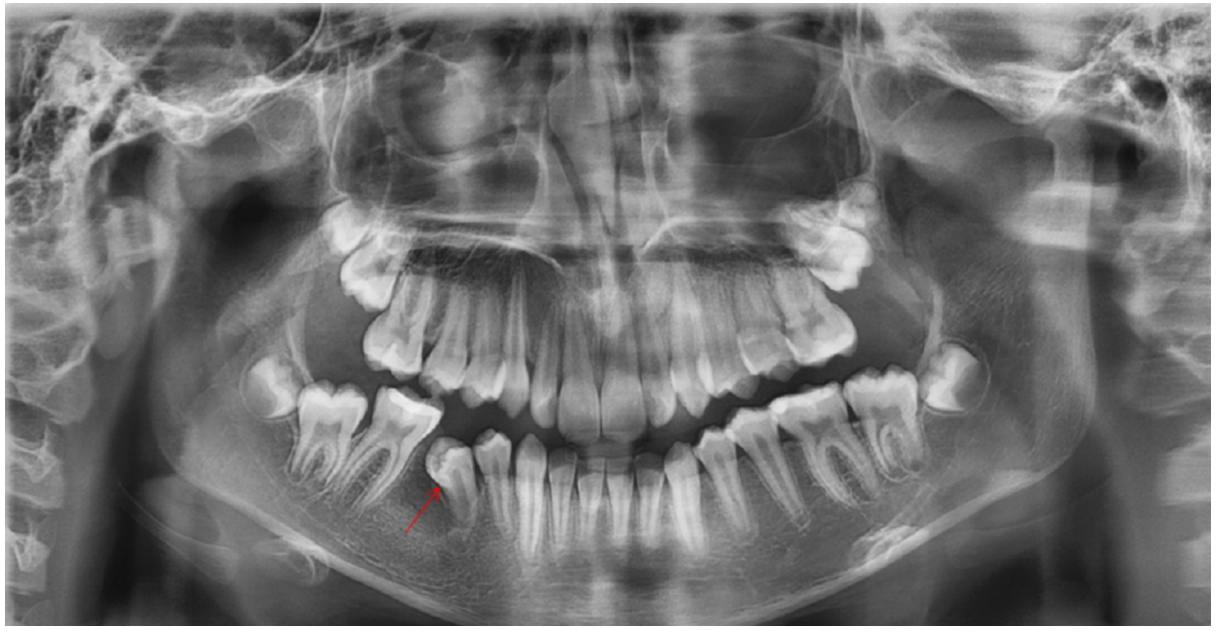

\section{FIGURE 5: Panoramic radiograph}

A panoramic radiograph taken after 1 year 8 months from the surgery showing regression of the lesion and the new position of the involved tooth 45 (red arrow).

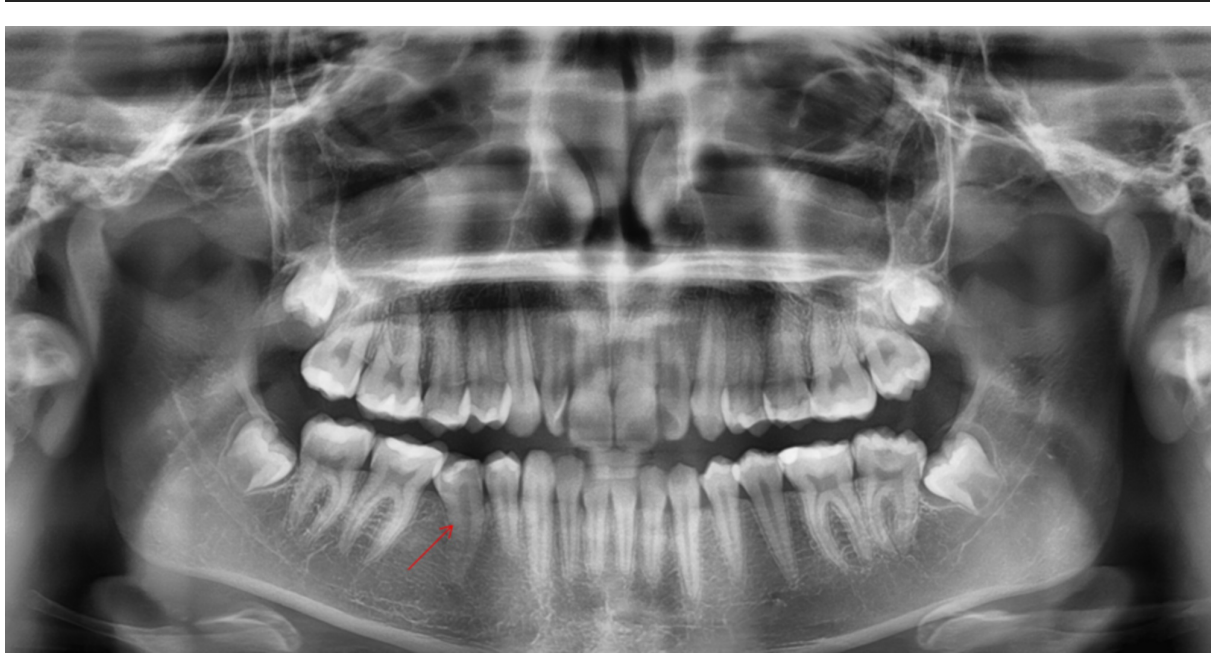

\section{FIGURE 6: Panoramic radiograph}

A panoramic radiograph taken after 5 years from the surgery showing complete regression of the lesion and eruption of the involved tooth 45 (red arrow)

\section{Discussion}

Although being the most frequent developmental odontogenic cyst to develop in the 2nd (23\% of all DCs) and 3rd (20\% of all DCs) decades of life, DC can also be found in the 4th, 5th, and 6th decades (17\%, $17 \%$, and $12 \%$, respectively) and less commonly in the 1 st and the 7 th decades and above $[2,4,14-16]$.

Many authors reported that the DC incidence rate is $14 \%$ to $34 \%$ of all jaw cysts with $45.7 \%$ of them involving the mandibular 3rd molar. Male patients are more affected compared to females; the reason of this sex predilection remains unclear $[4,16-18]$.

The treatment of choice of DC is the enucleation and the removal of the affected tooth; in the case of large cysts, an initial phase of marsupialization followed by the total enucleation is recommended. If DC is connected with a canine or a premolar with a positive eruptive position, marsupialization is preferred [2$3,10-11,12,14]$.

The prognosis of DC, after successful surgery, is usually excellent with low rate of recurrence.

On the other hand, because of the cases reported about the metaplastic or dysplastic changes of DC and its progression to more severe lesions such as ameloblastoma, mucoepidermoid carcinoma, and squamous cell 
In our case, we have presented a DC related to a second right mandibular premolar of a 10-year-old girl. A conservative treatment by marsupialization has been adopted leading to complete disappearance of the lesion and the eruption of the affected tooth with no recurrence after a five-year follow-up.

\section{Conclusions}

In front of unerupted teeth, thorough clinical and radiological assessments are obligatory in order to investigate the presence of DC. Despite the benignity of these lesions an appropriate treatment must be chosen with a long follow-up period to avoid more complicated situations. Marsupialization is a very effective method in treating DC in children where there is always a chance to save the affected teeth and restores the occlusal functions.

\section{Additional Information \\ Disclosures}

Human subjects: Consent was obtained by all participants in this study. Conflicts of interest: In compliance with the ICMJE uniform disclosure form, all authors declare the following: Payment/services info: All authors have declared that no financial support was received from any organization for the submitted work. Financial relationships: All authors have declared that they have no financial relationships at present or within the previous three years with any organizations that might have an interest in the submitted work. Other relationships: All authors have declared that there are no other relationships or activities that could appear to have influenced the submitted work.

\section{References}

1. Qian WT, Ma ZG, Xie QY, Cai XY, Zhang Y, Yang C: Marsupialization facilitates eruption of dentigerous cyst-associated mandibular premolars in preadolescent patients. J Oral Maxillofac Surg. 2013, 71:1825-1832. 10.1016/j.joms.2013.06.223

2. Mishra R, Tripathi AM, Rathore M: Dentigerous cyst associated with horizontally impacted mandibular second premolar. Int J Clin Pediatr Dent. 2014, 7:54-57. 10.5005/jp-journals-10005-1235

3. Jain N, Gaur G, Chaturvedy V, Verma A: Dentigerous cyst associated with impacted maxillary premolar: a rare site occurrence and a rare coincidence. Int J Clin Pediatr Dent. 2018, 11:50-52. 10.5005/jp-journals10005-1483

4. Zhang LL, Yang R, Zhang L, Li W, MacDonald-Jankowski D, Poh CF: Dentigerous cyst: retrospective clinicopathological analysis of 2082 dentigerous cysts in British Columbia, Canada. Int J Oral Maxillofac Surg. 2010, 39:878-882. 10.1016/j.ijom.2010.04.048

5. Shah N, Thuau H, Beale I: Spontaneous regression of bilateral dentigerous cysts associated with impacted mandibular third molars. Br Dent J. 2002, 192:75-76. 10.1038/sj.bdj.4801297

6. Kumar Mohapatra P, Joshi N: Conservative management of a dentigerous cyst associated with an impacted mandibular second premolar in mixed. J Dent Res Dent Clin Dent Prospects. 2009, 3:98-102. 10.5681/joddd.2009.025

7. Aher V, Chander PM, Chikkalingaiah RG, Ali FM: Dentigerous cysts in four quadrants: a rare and first reported case. J Surg Tech Case Rep. 2013, 5:21-26. 10.4103/2006-8808.118607

8. Batra P, Roychoudhury A, Balakrishan P, Prakash H: Bilateral dentigerous cyst associated with polymorphism in chromosome 1qh+. J Clin Pediatr Dent. 2004, 28:177-181. 10.17796/jcpd.28.2.m21q8vx78084374v

9. Ikeshima A, Tamura Y: Differential diagnosis between dentigerous cyst and benign tumor with an embedded tooth. J Oral Sci. 2002, 44:13-17. 10.2334/josnusd.44.13

10. Abu-Mostafa N, Abbasi A: Marsupialization of a large dentigerous cyst in the mandible with orthodontic extrusion of three impacted teeth. A case report. J Clin Exp Dent. 2017, 9:1162-1166. 10.4317/jced.53890

11. de Carvalho IK, Luna AH: Spontaneous eruption of premolar associated with a dentigerous cyst . Case Rep Dent. 2016, 2016:5323978. 10.1155/2016/5323978

12. Alnofaie H, Alomran O, Ababtain R, Alomar A : Spontaneous eruption of a deeply impacted premolar after conservative treatment of an associated dentigerous cyst: a case report. Cureus. 2019, 11:e6414. 10.7759/cureus.6414

13. Kirtaniya BC, Sachdev V, Singla A, Sharma AK: Marsupialization: A conservative approach for treating dentigerous cyst in children in the mixed dentition. J Indian Soc Pedod Prev Dent. 2010, 28:203-208. 10.4103/0970-4388.73795

14. Martínez-Pérez D, Varela-Morales M: Conservative treatment of dentigerous cysts in children: a report of 4 cases. J Oral Maxillofac Surg. 2001, 59:331-333. 10.1053/joms.2001.21006

15. Grossmann SM, Machado VC, Xavier GM, et al.: Demographic profile of odontogenic and selected nonodontogenic cysts in a Brazilian population. Oral Surg Oral Med Oral Pathol Oral Radiol Endod. 2007, 104:35-41. 10.1016/j.tripleo.2007.05.028

16. Regezi JA, Sciubba JJ: Cysts of the Oral Region. Oral Pathology: Clinical Pathologic Correlations. Saunders Co, Philadelphia; 1999. 288:321.

17. Benn A, Altini M: Dentigerous cysts of inflammatory origin: a clinicopathologic study . Oral Surg Oral Med Oral Pathol Oral Radiol Endod. 1996, 81:203-209. 10.1016/s1079-2104(96)80416-1

18. Ustuner E, Fitoz S, Atasoy C, Erden I, Akyar S: Bilateral maxillary dentigerous cysts: a case report . Oral Surg Oral Med Oral Pathol Oral Radiol Endod. 2003, 95:632-635. 10.1067/moe.2003.123

19. Shibata Y, Asaumi J, Yanagi Y, et al.: Radiographic examination of dentigerous cysts in the transitional 


\section{Cureus}

dentition. Dentomaxillofac Radiol. 2004, 33:17-20. 10.1259/dmfr/24148363

20. Vasiapphan H, Christopher PJ, Kengasubbiah S, Shenoy V, Kumar S, Paranthaman A: Bilateral dentigerous cyst in impacted mandibular third molars: a case report. Cureus. 2018, 10:3691. 10.7759/cureus.3691 